\title{
Methylation analysis of tumor suppressor genes in endometroid carcinoma of endometrium using MS-MLPA
}

\author{
Eva Dvorakova ${ }^{a}$, Marcela Chmelarova ${ }^{b}$, Jan Lacoc, Vladimir Palicka ${ }^{b}$, Jiri Spacek ${ }^{a}$
}

\begin{abstract}
Background. Epigenetic changes are considered to be a frequent event during tumor development. Hypermethylation of promoter $\mathrm{CpG}$ islands represents an alternative mechanism for inactivation of tumor suppressor genes, DNA repair genes, cell cycle regulators and transcription factors. The aim of this study was to investigate promoter methylation of specific genes in endometrial cancer by comparison with normal endometrial tissue.

Materials and Methods. We used MS-MLPA (Methylation-specific Multiplex ligation-dependent probe amplification) to compare the methylation status of 59 tissue samples of endometroid type of endometrial carcinoma with 20 control samples of non-neoplastic endometrium.

Results. Using 15\% cut-off for methylation, we observed significantly higher methylation in the CDH13 gene in endometrial cancer group. We observed significantly higher methylation in both WT1 and GATA5 genes in IB stage of endometroid carcinoma. We also observed significantly higher methylation in GATA5 gene in the group of poorly differentiated endometroid carcinoma.

Conclusion. The findings suggest the importance of hypermethylation of CDH13, WT1 and GATA5 genes in endometrial carcinogenesis and could have implications for future diagnostic and therapeutic strategies of endometrial cancer based on epigenetic changes.
\end{abstract}

Key words: MS-MLPA, DNA methylation, endometrial cancer, CDH13, WT1, GATA5, epigenetics

Received: November 28, 2012; Accepted: April 26, 2013; Available online: May 29, 2013

http://dx.doi.org/10.5507/bp.2013.035

${ }^{a}$ Department of Obstetrics and Gynecology, Faculty of Medicine in Hradec Kralove, Charles University in Prague and University Hospital Hradec Kralove, Hradec Kralove, Czech Republic

'Institute for Clinical Biochemistry and Diagnostics, Faculty of Medicine in Hradec Kralove, Charles University in Prague and University Hospital Hradec Kralove, Hradec Kralove

'The Fingerland Department of Pathology, Faculty of Medicine in Hradec Kralove, Charles University in Prague and University Hospital Hradec Kralove, Hradec Kralove

Corresponding author: Eva Dvorakova, e-mail:evajurkova@seznam.cz

\section{INTRODUCTION}

Endometrial cancer is one of the three most common cancers in females in well developed countries. The vast majority of cases are diagnosed after the menopause, with the highest incidence around the seventh decade of life. The risk factors for the disease include obesity, hypertension, diabetes mellitus, late menopause and unopposed estrogen use ${ }^{1}$. For all stages, the overall 5-year survival is around $80 \%$. Two types of endometrial carcinoma are distinquished with respect to molecular genetic changes, biologic behaviour and prognosis: type I- endometroid and type II- non-endometroid carcinoma ${ }^{2}$.

Aberrant methylation of normally unmethylated $\mathrm{CpG}$ islands, located in the $5^{\prime}$ promoter region of genes, has been associated with transcriptional inactivation of several genes in human cancer, and can serve as an alternative to mutational inactivation ${ }^{3}$. Molecular events associated with tumor methylation hold promises for cancer risk assessment, diagnostic purpose and prognosis ${ }^{4}$. Moreover, epigenetic alterations are potentially reversible effects, which could be used for new therapeutic strategies in the future. Several methylation markers have been identified in endometrial cancer: $h M L H 1, H O X A 10, H O X A 11$,
THBS2, CDH13, HSPA2, RASSF1A, SOCS2, PER1, RARB2, GSTP1, SFN (14-3-3 sigma), SESN3 and TITF1 (ref. ${ }^{5-8}$ ).

A number of methods have been developed for detection of methylation alterations in tumors, such as MSP (Methylation-specific PCR), MS-MLPA (Methylationspecific Multiplex ligation-dependent probe amplification), MS-HRM (Methylation-sensitive High resolution melting), DNA sequencing, microarrays and others ${ }^{9}$. Among these, MS-MLPA represents a rather novel costeffective and time-efficient method and furthermore is an ideal technique to use in FFPE (formalin-fixed, paraffinembedded) samples ${ }^{10}$. It permits simultaneous identification of epigenetic alterations in a predefined set of up to 25 genes. The present study applies a MS-MLPA analysis in endometrial cancer.

\section{MATERIALS AND METHODS}

Formalin-fixed and paraffin-embedded samples from both endometroid carcinoma of endometrium and normal endometrial tissue were obtained from 79 women ( 59 patients with endometrial cancer, 20 patients with normal endometrium) treated at the Department of Obstetrics 
Table 1. Genes in the methylation-specific multiplex ligation-dependent probe amplification (MS-MLPA) KIT ME002 Tumor suppressor-2 (MRC Holland).

\begin{tabular}{|c|c|c|c|}
\hline Gene & Name & Probes & Chromosomal location \\
\hline BRCA1 & Breast cancer 1 & 03296-L01269 & $17 \mathrm{q} 21.3$ \\
\hline BRCA2 & Breast cancer 2 & 02285-L01776 & $13 q 13.1$ \\
\hline ATM & Ataxia telangiectasia mutated & 03023-L02413 & $11 q 23$ \\
\hline TP53 & Tumor protein $\mathrm{p} 53$ & 02374-L02530 & $17 \mathrm{p} 13.1$ \\
\hline PTEN & Phosphatase and tensin homolog & 03808-L02169 & $10 \mathrm{q} 23.3$ \\
\hline MGMTa & O-6-methylguanine-DNA methyltransferase & 05670-L05146 & $10 \mathrm{q} 26.3$ \\
\hline PAX5 & Paired box gene 5 & 03750-L03210 & $9 \mathrm{p} 13$ \\
\hline CDH13 & Cadherin 13, H-cadherin & 02257-L01742 & $16 \mathrm{q} 23.3$ \\
\hline TP73 & Tumor protein $\mathrm{p} 73$ & 01684-L01264 & $1 \mathrm{p} 36.3$ \\
\hline WT1 & Wilms tumor 1 & 02755-L02204 & $11 \mathrm{p} 13$ \\
\hline VHL & von Hippel-Lindau tumor suppressor & 03818-L03850 & $3 \mathrm{p} 25.3$ \\
\hline GSTP1 & Glutathione S-transferase pi 1 & 02747-L02174 & $11 \mathrm{q} 13$ \\
\hline CHFR & Checkpoint with forkhead and ring finger domains & 02737-L02164 & $12 \mathrm{q} 24.3$ \\
\hline ESR1 & Estrogen receptor 1 & 02746-L02173 & $6 \mathrm{q} 25.1$ \\
\hline RB1a & Retinoblastoma 1 & 02734-L02161 & $13 q 14.2$ \\
\hline MSH6 & MutS homolog 6 & 01250-L00798 & $2 \mathrm{p} 16.3$ \\
\hline MGMTb & O-6-methylguanine-DNA methyltransferase & 13716-L15582 & $10 \mathrm{q} 26.3$ \\
\hline THBS1 & Thrombospondin 1 & 01678-L17140 & $15 \mathrm{q} 15$ \\
\hline CADM1 & Cell adhesion molecule 1 & 03816-L17141 & $11 \mathrm{q} 23$ \\
\hline STK1 & Serine/threonine protein kinase & 06783-L17143 & $19 \mathrm{q} 13.3$ \\
\hline PYCARD & PYD and CARD domain containing & 02252-L01737 & 16 p11.2 \\
\hline PAX6 & Paired box gene 6 & 03749-L03209 & $11 \mathrm{p} 13$ \\
\hline CDKN2A & Cyclin-dependent kinase inhibitor $2 \mathrm{~A}$ & 01530-L00955 & $9 \mathrm{p} 21.3$ \\
\hline GATA5 & GATA-binding protein 5 & 03752-L06199 & $20 \mathrm{q} 13.3$ \\
\hline RARB & Retinoic acid receptor, beta & 04046-L02172 & $3 \mathrm{p} 24.2$ \\
\hline CD44 & CD44 molecule (Indian blood group) & 04500-L02761 & $11 \mathrm{p} 12$ \\
\hline $\mathrm{RB} 1 \mathrm{~b}$ & Retinoblastoma 1 & 04502-L02199 & $13 q 14.2$ \\
\hline
\end{tabular}

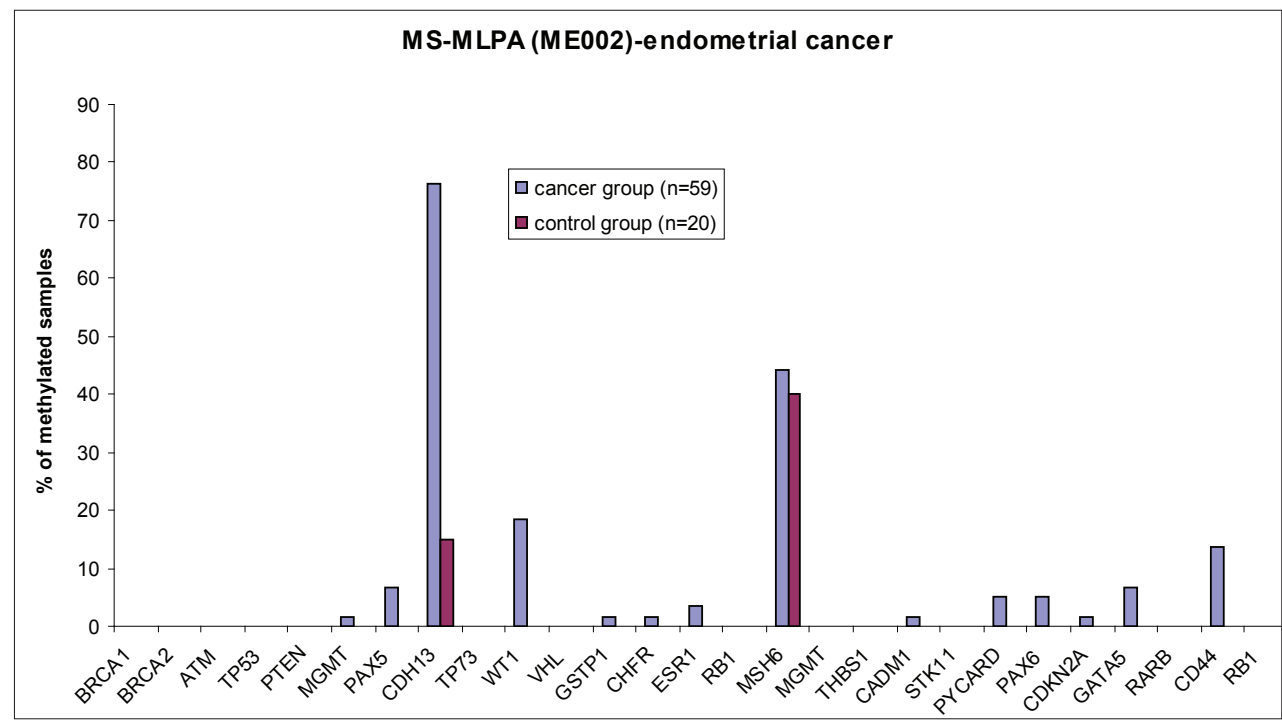

Fig. 1. Comparison of methylation frequencies (cut-off value 15\%) of the 25 analyzed genes in endometrial cancer and control samples. There is significantly higher methylation in $C D H 13$ gene $(P<0.001)$ in endometrial carcinoma group compared with control group. 


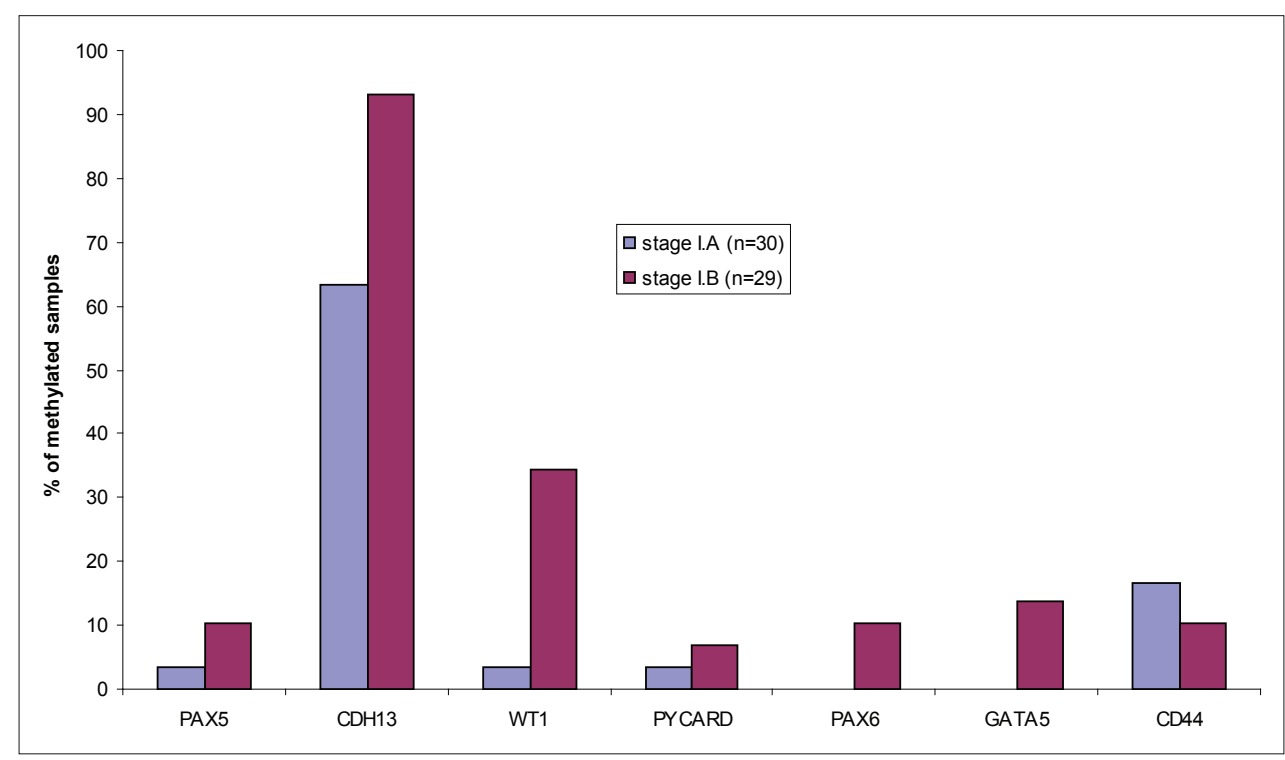

Fig. 2. Methylation of specific genes according to tumor stage. There is significantly higher methylation in WT1 $(P=0.002)$ and GATA5 $(P=0.05)$ genes in stage IB of endometrial carcinoma samples compared with stage IA samples.

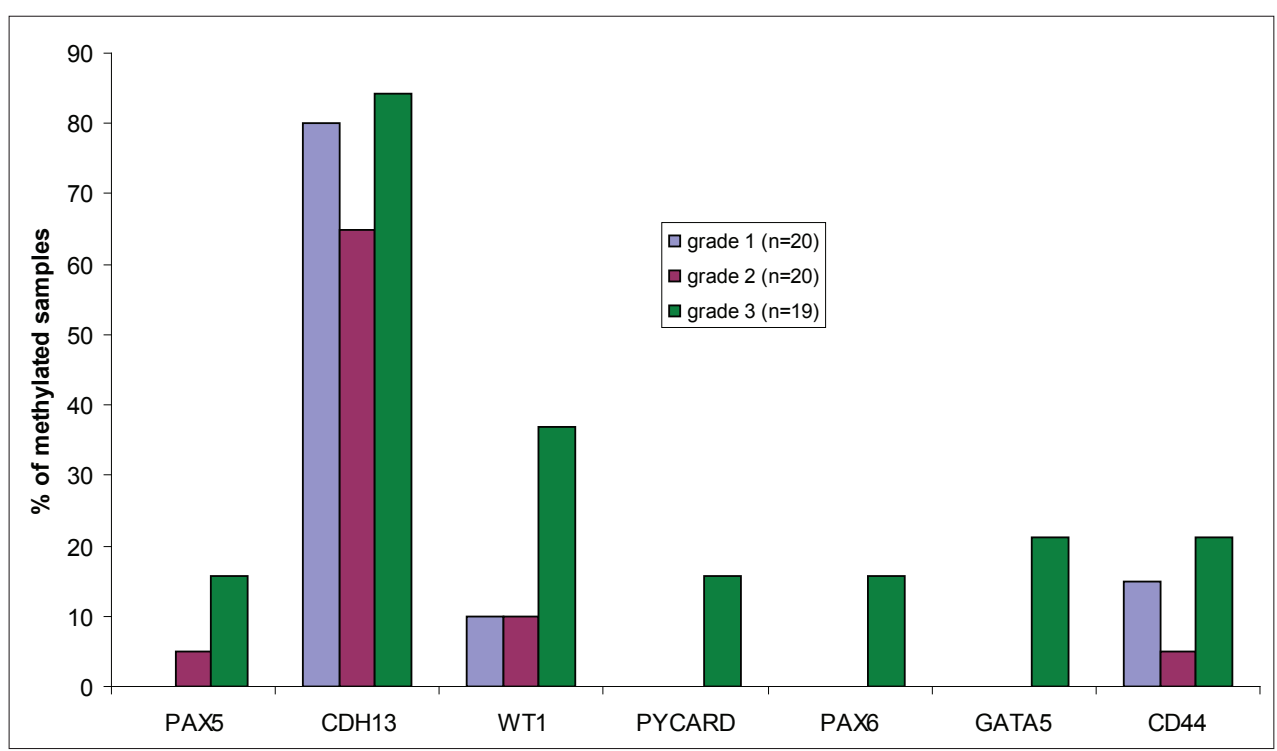

Fig. 3. Methylation of specific genes according to tumor grade. There is significantly higher methylation in GATA5 gene $(P=0.05)$ in poorly differentiated carcinoma compared with grade 1 and grade 2 tumor samples.

and Gynecology, University Hospital Hradec Kralove, Czech Republic. The samples of normal endometrium were obtained from patients surgically treated for non-malignant diagnosis. The paraffin blocks were retrieved from the archive of the Fingerland Department of Pathology, University Hospital Hradec Kralove. All slides were reviewed by an experienced pathologist (J.L.). The tumors were classified according to the current WHO classification of tumors of the female reproductive system ${ }^{11}$. The following clinicopathological data was recorded: patient's age, tumor stage and tumor grade. The study was approved by the Ethics Committee of University Hospital Hradec Kralove.
DNA was extracted from formalin-fixed, paraffin embedded samples using a Qiagen DNA extraction kit.

\section{Methylation-Specific Multiplex Ligation-Dependent Probe Amplification (MS-MLPA)}

The present study used the MS-MLPA probe set ME002-B1 (MRC-Holland, Amsterdam, The Netherlands), which can simultaneously check for aberrant methylation in 25 tumor suppressor genes (Table 1). Probe sequences, gene loci and chromosome locations can be found at http://www.mlpa.com. Individual genes were evaluated by two probes, which recognized different Hhal restriction sites in their regions. The experimental 
procedure was carried out according to the manufacturer's instructions, with minor modifications.

In short, DNA (100 ng) was dissolved up to $5 \mu \mathrm{L}$ TE-buffer (10 mM Tris.Cl; 0.5 mM EDTA; pH 9.0) denatured and subsequently cooled down to $25^{\circ} \mathrm{C}$. After adding the probe mix, the probes were allowed to hybridize (overnight at $60{ }^{\circ} \mathrm{C}$ ). Subsequently, the samples were divided into two: in one half, the samples were directly ligated, while for the other half ligation was combined with the HhaI digestion enzyme. This digestion resulted in ligation of the methylated sequences only. PCR was performed on all the samples using a standard thermal cycler (GeneAmp 9700, Applied Biosystems, Foster City, CA, USA), with 35 cycles of denaturation at $95{ }^{\circ} \mathrm{C}$ for $30 \mathrm{~s}$, annealing at $60^{\circ} \mathrm{C}$ for $30 \mathrm{~s}$ and extension at $72^{\circ} \mathrm{C}$ for $1 \mathrm{~min}$ with a final extension of $20 \mathrm{~min}$ at $72^{\circ} \mathrm{C}$. Aliquots of $0.6 \mu \mathrm{L}$ of the PCR reaction were combined with $0.2 \mu \mathrm{L}$ LIZ-labeled internal size standard (Applied Biosystems), and $9.0 \mu \mathrm{L}$ deionized formamide. After denaturation, fragments were separated and quantified by electrophoresis on an ABI 3130 capillary sequencer and analyzed using GeneMapper4.0 (both Applied Biosystems). Peak identification and values corresponding to peak size in base pairs (bp), and peak areas were used for further data processing. Methylation dosage ratio was obtained by the following calculation: $\mathrm{Dm}=\left(\mathrm{P}_{\mathrm{x}} / \mathrm{P}_{\text {ctrl }}\right) \mathrm{Dig} /\left(\mathrm{P}_{\mathrm{x}} / \mathrm{P}_{\text {ctrl }}\right)$ Undig, where $\mathrm{Dm}$ is the methylation dosage ratio, $\mathrm{P}_{\mathrm{x}}$ is the peak area of a given probe, $\mathrm{P}_{\text {ctrl }}$ is the sum of the peak areas of all control probes, Dig stands for HhaI digested sample and Undig for undigested sample. Dm can vary between 0 and 1.0 (corresponding to $0-100 \%$ of methylated DNA). Based on previous experiments, we considered a promoter to show methylation if the methylation dosage ratio was $\geq 0.15$, which corresponds to $15 \%$ of methylated DNA (ref. ${ }^{12}$ ). CpG universal methylated and unmethylated DNA (Chemicon International, Temecula, CA) were used in every run as controls.

\section{Statistical analysis}

Proportions were compared by two-tailed Fisher's exact test. Associations with $P$-value $<0.05$ were considered to be significant.

\section{RESULTS}

In the present study we analyzed 79 samples of endometrial tissue (59 samples of endometroid carcinoma and 20 samples of normal endometrium). The median age of patients at the time of diagnosis was 65 years (range 44-84 years) in the carcinoma group and 60 years (range 50-79 years) in the control group.

We used the MS-MLPA probe set ME002 (MRCHolland, Amsterdam, The Netherlands) to analyze samples of endometrium. Using $15 \%$ cut-off for methylation we observed statistically-significant higher methylation in $C D H 13$ gene $(P<0.001)$ and higher methylation in $W T 1$ gene $(P=0.057)$ in endometrial cancer patients compared to control group. For MSH6 gene we observed high methylation (about 40\%) in both endometrial can- cer and control samples. For genes $B R C A 1, B R C A 2, A T M$, TP53, PTEN, TP73, VHL, RB1, THBS1, STK11 and RARB, the methylation rate did not exceed the $15 \%$ threshold; the remaining genes also showed relevant differences in methylation between endometrial carcinoma and control samples (Fig. 1).

The methylation results from the endometrial cancer specimens were compared with clinicopathological characteristics, including tumor grade and tumor stage (pTNM). Both WT1 $(P=0.002)$ and GATA5 $(P=0.05)$ genes showed significantly higher methylation in stage IB compared with stage IA of endometrial cancer samples (Fig. 2). Methylation in GATA5 gene $(P=0.05)$ was significantly higher in grade 3 of endometrial cancer samples compared with the group of grade 1 and grade 2 tumors (Fig. 3).

\section{DISCUSSION}

Endometrial carcinoma is the most common malignant tumor of the female genital system in developed countries. The biological features of endometrial cancer are determined by the underlying molecular alterations of tumor cells, including epigenetic inactivation of tumor suppressor genes as well as mutations and deletions. It is now clear that de novo promoter methylation is common mechanism for inactivation of tumor suppressor genes ${ }^{3}$. The promoter methylation status has been reported in several human neoplasms. The purpose of this study was to investigate promoter methylation in the set of common tumor suppressor genes in 59 endometrial cancer and 20 control samples. We used MS-MLPA and a threshold of $15 \%$ methylation was applied based on previous study ${ }^{12}$.

We observed significantly higher methylation in CDH13 gene and higher methylation in WT1 and CD44 genes in endometrial cancer compared with non-neoplastic samples indicating that promoter methylation of these tumor suppressor genes may play an important role in endometrial carcinogenesis. These findings could have implications for future diagnostic and therapeutic strategies of endometrial cancer based on epigenetic changes.

MSH6 was previously shown to be frequently methylated in breast cancer and also in normal breast tissue ${ }^{12}$. In the present study, MSH6 methylation was very frequent in both endometrial cancer and normal endometrial tissue (Fig. 1).

The gene CDH13 (H-cadherin) encodes a member of the cadherin superfamily. The protein acts as a negative regulator of axon growth during neural differentiation, protects vascular endothelial cells from apoptosis due to oxidative stress and is associated with resistance to atherosclerosis. The gene is hypermethylated in many types of human cancer including ovarian and endometrial carcinomas ${ }^{13,14}$. In the study using MS-MLPA probe mix ME001, targeting different $\mathrm{CpG}$ islands within promoter region of the $\mathrm{CDH} 13$ gene, $93 \%$ of samples were methylated ${ }^{14}$. In our study, we observed almost $80 \%$ of methylated carcinoma samples. Methylation of $C D H 1$ (E-cadherin), another member of cadherin superfamily, 
is also important event in endometrial carcinogenesis ${ }^{15}$. Aberrant methylation in promoter region of $C D H 1$ gene is associated with poor differentiation and myometrial invasion in endometrial carcinomas suggesting its possible role in tumor progression ${ }^{16}$. However, no association between $C D H 1$ hypermethylation and clinicopathological or immunohistological characteristics of endometrial cancer was found in other studies ${ }^{17,18}$.

CD44 is a transmembrane receptor protein that belongs to the family of adhesion molecules and has a critical role in extracellular matrix adhesion and is implicated in a series of cellular events, such as lymphocyte homing, leukocyte activation, lymphopoiesis, embryogenesis, and wound healing ${ }^{19}$. With regard to $C D 44$ and its variants, several studies have investigated its expressions in endometrial pathologies, including adenocarcinomas ${ }^{20-25}$. In our study we observed higher methylation in CD44 gene, but with no statistical significance.

According to tumor stage and grade we observed significantly higher methylation of WT1 $(P=0.002)$ and GATA5 $(P=0.05)$ genes in stage IB of endometrial carcinoma (Fig. 2) and significantly higher mehylation of GATA5 gene $(P=0.05)$ in grade 3 of endometrial carcinoma (Fig. 3). These findings suggest that hypermethylation in WT1 and GATA5 genes could play an important role in tumor myometrial invasion and its aggressive behavior.

The Wilms' tumor gene WT1 is overexpressed in various kinds of solid tumors. However, it remains unclear whether WT1 plays a pathophysiological role in endometrial cancer ${ }^{26,27}$. The GATA family of transcription factors plays essential role in cell growth and differentiation during embryogenesis and early development ${ }^{28}$. GATA5 have been implicated as important regulators in the normal development and differentiation of mesoderm- and endoderm-derived tissues, including lung, liver, gonad and pancreas $^{29}$. Loss of GATA4 and GATA5 expression second to promoter hypermethylation has been identified in primary ovarian, lung and gastrointestinal cancer ${ }^{30-33}$. Our present study is the first study to demonstrate methylation of GATA5 in endometrial cancer.

There is an emerging evidence that epigenetic regulation of gene expression is at least as important to carcinogenesis as genetic disruption and more studies are needed to characterize the aberrant DNA methylation profile of endometrial carcinoma.

In conclusion, our study showed that there is significantly higher methylation in $C D H 13$ gene in the endometrial cancer group compared with samples of nonneoplastic endometrium. We also observed significantly higher methylation in WT1 and GATA5 genes in stage IB compared with stage IA of endometrial cancer samples. According to tumor grade, there was significantly higher methylation in GATA5 gene in grade 3 of endometrial cancer samples compared with the group of grade 1 and grade 2 samples. The findings suggest the importance of hypermethylation of these genes in endometrial carcinogenesis and could have implications for future diagnostic and therapeutic strategies of endometrial cancer based on epigenetic changes.

\section{ABBREVIATIONS}

MS-MLPA, Methylation-specific Multiplex ligationdependent probe amplification; MSP, Methylation specific PCR; PCR, Polymerase chain reaction; DNA, Deoxyribonucleic acid; MS-HRM, Methylation-sensitive High resolution melting; FFPE, Formalin-fixed, paraffinembedded; WHO, World Health Organization; EDTA, Ethylenediaminetetraacetic acid; pTNM, pathologic TNM - T (tumor), N (nodes), M (metastasis).

\section{ACKNOWLEDGEMENTS}

This study was supported by Grant GAUK No.157310 and by research project PRVOUK of the Charles University in Prague.

\section{CONFLICT OF INTEREST STATEMENT}

Author's conflicts of interest disclosure: None declared.

\section{REFERENCES}

1. Liu F-S. Molecular carcinogenesis of endometrial cancer. Taiwaneses J Obstet Gynecol 2007;46:26-32.

2. Sherman ME, Bur ME, Kurman RJ. p53 in endometrial cancer and its putative precursors: evidence for diverse pathways of tumorogenesis. Hum Pathol 1995;26:1268-74.

3. Jones PA, Baylin SB. The epigenomics of cancer. Cell 2007;128:683-92.

4. Clark SJ, Melki J. DNA methylation and gene silencing in cancer: which is the guilty party? Oncogene 2002;21:5380-7.

5. Whitcomb BP, Mutch DG, Herzog TJ, Rader JS, Gibb RK, Goodfellow PJ. Frequent HOXA11 and THBS2 promoter methylation, and a methylator phenotype in endometrial adenocarcinoma. Clin Cancer Res 2003;9:2277-87.

6. Mhawech P, Benz A, Cerato C, Greloz V, Assaly M, Desmond JC, Koeffler HP, Lodygin D, Hermeking $H$, Herrmann F, Schwaller J. Downregulation of 14-3-3sigma in ovary, prostate and endometrial carcinomas is associated with CpG island methylation. Mod Pathol 2005; 18:340-8.

7. Yeh KT, Yang MY, Liu TC, Chen JC, Chan WL, Lin SF, Chang JG. Abnormal expression of period 1 (PER1) in endometrial carcinoma. J Pathol 2005;206:111-20.

8. Yoshida H, Broaddus R, Cheng W, Xie S, Naora H. Deregulation of the HOXA10 homeobox gene in endometrial carcinoma: role in epithelial-mesenchymal transition. Cancer Res 2006;66:889-97.

9. Chmelarova M, Palicka V. The most frequent methods used for DNA methylation analysis. Cas Lek Cesk 2011;150:442-5.

10. Nygren AO, Ameziane N, Duarte HM, Vijzelaar RN, Waisfisz Q, Hess CJ, Schouten JP, Errami A. Methylation-specific MLPA (MS-MLPA): simultaneous detection of CPG methylation and copy number changes of up to 40 sequences. Nucleic Acids Res 2005;33,e128.

11. Tavassoli F.A, Devilee P. (Eds.): (2003) World Health Organization Classification of Tumors. Pathology and Genetics of Tumors of the Breast and Female Genital Organs. IARC Press: Lyon 2003:113-202.

12. Moelans $C B$, Verschuur-Maes $A H$, van Diest PJ. Frequent promoter hypermethylation of BRCA2, CDH13, MSH6, PAX5, PAX6 and WT1 in ductal carcinoma in situ and invasive breast cancer. J Pathol 2011;225:222-31.

13. Bol GM, Suijkerbuijk KP, Bart J, Vooijs M, van der Wall E, van Diest PJ. Methylation profiles of hereditary and sporadic ovarian cancer. Histopathology 2010;57:363-70.

14. Seeber LM, Zweemer RP, Marchionni L, Massuger LF, Smit VT, van Baal WM, Verheijen RH, van Diest PJ. Methylation profiles of en- 
dometrioid and serous endometrial cancers. Endocr Relat Cancer 2010;17:663-73.

15. Di Domenico M, Santoro A, Ricciardi C, laccarino M, laccarino S, Freda M, Feola A, Sanguedolce F, Losito S, Pasquali D, Di Spiezio Sardo A, Bifulco G, Nappi C, Bufo P, Guida M, De Rosa G, Abbruzzese A Caraglia M, Pannone G. Epigenetic fingerprint in endometrial carcinogenesis: the hypothesis of a uterine field cancerization. Cancer Biol Ther 2011;12:447-57.

16. Saito T, Nishimura M, Yamasaki H, Kudo R. Hypermethylation in promoter region of $\mathrm{E}$-cadherin gene is associated with tumor dedifferention and myometrial invasion in endometrial carcinoma. Cancer 2003;97:1002-9.

17. Banno K, Yanokura M, Susumu N, Kawaguchi M, Hirao N, Hirasawa A, Tsukazaki K, Aoki D. Relationship of the aberrant DNA hypermethylation of cancer-related genes with carcinogenesis of endometrial cancer. Oncol Rep 2006;16:1189-96.

18. Pijnenborg JM, Kisters N, van Engeland M, Dunselman GA, de Haan J, de Goeij AF, Groothuis PG. APC, beta-catenin and E-cadherin and the development of recurrent endometrial carcinoma. Int J Gynecol Cancer 2004;14:947-56.

19. Sneath RJ, Mangham DC. The normal structure and function of CD44 and its role in neoplasia. Mol Pathol 1998;51:191-200.

20. Leblanc M, Poncelet C, Soriano D, Walker-Combrouze F, Madelenat P, Scoazec JY, Darai E. Alteration of CD44 and cadherins expression: possible association with augmented aggressiveness and invasiveness of endometrial carcinoma. Virchows Arch 2001;438:78-85.

21. Ayhan A, Tok EC, Bildirici I, Ayhan A. Overexpression of CD44 variant 6 in human endometrial cancer and its prognostic significance. Gynecol Oncol 2001;80:355-8.

22. Stokes GN, Shelton JB Jr, Zahn CM, Kendall BS. Association of CD44 isoform immunohistochemical expression with myometrial and vascular invasion in endometrioid endometrial carcinoma. Gynecol Oncol 2002;84:558-61.
23. Afify AM, Craig S, Paulino AF, Stern R. Expression of hyaluronic acid and its receptors, CD44s and CD44v6, in normal, hyperplastic, and neoplastic endometrium. Ann Diagn Pathol 2005;9:312-8.

24. Hong SC, Song JY, Lee JK, Lee NW, Kim SH, Yeom BW, Lee KW. Significance of CD44v6 expression in gynecologic malignancies. J Obstet Gynaecol Res 2006;32:379-86.

25. Saegusa M, Hashimura M, Okayasu I. CD44 expression in normal, hyperplastic, and malignant endometrium. J Pathol 1998;184:297306.

26. Dohi S, Ohno S, Ohno Y, Kyo S, Soma G, Sugiyama H, Inoue M. WT1 expression correlates with angiogenesis in endometrial cancer tissue. Anticancer Res 2010;30:3187-92.

27. Ohno S, Dohi S, Ohno Y, Kyo S, Sugiyama H, Suzuki N, Inoue M. Immunohistochemical detection of WT1 protein in endometrial cancer. Anticancer Res 2009;29:1691-5.

28. Patient RK, McGhee JD. The GATA family (vertebrates and invertebrates). Curr Opin Genet Dev 2002;12:416-22.

29. Molkentin JD. The zinc finger-containing transcription factors GATA4, -5, and -6: Ubiquitously expressed regulators of tissue-specific gene expression. J Biol Chem 2000;275:38949-52.

30. Guo M, Akiyama Y, House MG, Hooker CM, Heath E, Gabrielson E, Yang SC, Han Y, Baylin SB, Herman JG, Brock MV. Hypermethylation of the GATA genes in lung cancer. Clin Cancer Res 2004;10:7917-24.

31. Guo M, House MG, Akiyama Y, Qi Y, Capagna D, Harmon J, Baylin SB, Brock MV, Herman JG. Hypermethylation of the GATA gene family in esophageal cancer. Int J Cancer 2006;119:2078-83.

32. Akiyama $Y$, Watkins $N$, Suzuki $H$, Jair KW, van Engeland $M$, Esteller M, Sakai H, Ren CY, Yuasa Y, Herman JG, Baylin SB. GATA-4 and GATA5 transcription factor genes and potential downstream antitumor target genes are epigenetically silenced in colorectal and gastrin cancer. Mol Cell Biol 2003;23:8429-39.

33. Wakana K, Akiyama Y, Aso T, Yuasa Y. Involvement of GATA-4/-5 transcription factors in ovarian carcinogenesis. Cancer Lett 2006;241:281-8. 